\title{
Game Edukasi Aksara Jawa 3D dengan Accelerometer
}

\author{
Affan Hensetiaji Widya ${ }^{1 *}$, Mustagfirin \\ 1,2,3 Jurusan TEKNIK INFORMATIKA, Fakultas TEKNIK, Universitas Wahid Hasyim \\ J1. Menoreh Tengah X/22, Sampangan, Semarang 50236. \\ *Email: ahensetiaji@gmail.com
}

\begin{abstract}
Abstrak
Aksara Jawa merupakan budaya peninggalan leluhur bangsa Indonesia khususnya di pulau Jawa yang digunakan masyarakat Jawa pada masa lampau untuk menulis dan membaca. Pada kemajuan ilmu teknologi saat ini belajar aksara jawa semakin kurang diminati dibandingkan dengan bermain. Setelah adanya observasi dan wawancara pada SDN Pedalangan 03 Semarang dapat disimpulkan bahwa selama pembelajaran, siswa kurang tertarik untuk belajar aksara jawa, oleh karena itu diperlukan metode yang membuat siswa tertarik untuk belajar. Pengembangan game edukasi aksara jawa 3D dengan accelerometer merupakan salah satu upaya untuk menarik minat siswa dalam belajar aksara jawa. Game ini menggunakan metode pengembangan sistem multimedia yang meliputi 6 tahap yaitu concept, design, collecting content material, assembly, testing, dan distribution. Terbukti aplikasi dapat menarik minat siswa untuk mengenal dan belajar aksara jawa.
\end{abstract}

Kata kunci: accelerometer, aksara jawa, game, multimedia

\section{PENDAHULUAN}

Indonesia merupakan negara yang kaya akan bahasa salah satunya yaitu bahasa Jawa. Bahasa Jawa merupakan salah satu dari bahasa daerah yang dimiliki bangsa Indonesia yang memiliki keaksaraan khusus yaitu aksara Jawa (Avianto dan Prasida, 2018). Aksara Jawa merupakan bukti nyata budaya peninggalan leluhur yang dimiliki bangsa Indonesia khususnya di pulau Jawa yang digunakan masyarakat Jawa pada masa lampau untuk menulis dan membaca. Saat ini aksara jawa mulai jarang ditemui dikarenakan perkembangan jaman dan jarang digunakan dalam kehidupan sehari-hari. Salah satu upaya pelestarian aksara Jawa yang dilakukan pemerintah saat ini yaitu dengan kurikulum pendidikan muatan lokal mata pelajaran bahasa jawa.

Setelah penulis melakukan observasi dan wawancara di SDN Pedalagan 03 Banyumanik Kota Semarang dapat disimpulkan bahwa anakanak kurng tertarik dan bersemangat dalam belajar aksara Jawa dan permasalahan pada pembelajaran ini ketika saat diluar sekolah atau di rumah murid-murid jarang belajar aksara Jawa. Setelah di teliti lebih lanjut hal tersebut dikarenakan media belajar yang digunakan kurang menarik bagi murid, pada dasarnya tidak semua murid akan paham akan materi yang diberikan secara konvensional dan beberapa murid akan cepat bosan ketika mendengarkan guru menjelaskan di papan tulis dan membaca buku. Pada usia yang masih anak-anak cenderung lebih suka bermain.

Seiring dengan kemajuan teknologi saat ini yang berkembang dengan pesat, tentunya membawa dampak pada setiap aspek kehidupan termasuk juga pada sistem pendidikan. Seiring lahirnya alat-alat canggih seperti komputer, laptop dan yang paling berkembang yaitu smartphone, ilmu dapat diperoleh dengan begitu mudah selain dengan buku. Salah satu aspek yang terpengaruh teknologi tersebut yaitu bidang pembelajaran yang telah mengunakan media digital sebagai media untuk belajar. Media digital dalam hal ini yaitu media elektronik seperti TV, radio, komputer, smartphone, yang terkomputerisasi (diproses melalui kompter) dan dipublish dalam bentuk gambar statis elektronik (poster digital), gambar bergerak (video, animasi, motion graphic), aplikasi interaktif (website, apps, media interaktif), serta augmented reality dan virtual reality (Mustagfirin dkk, 2019). Di dalam media digital tentunya memiliki berbagai macam multimedia salah satu nya yaitu penggunaan aplikasi android, dalam perkembangan aplikasi sendiri memiliki banyak jenis dan fungsi yang beraneka ragam.

Game merupakan salah satu jenis aplikasi yang dapat dimainkan di smartphone berbasis android. Seiring berkembangnya teknologi, game juga mengalami perkembangan dan 
memiliki berbagai bentuk dan jenis. Salah satu diantaranya yaitu game dengan fitur accelerometer sebagai control gerak. Accelerometer merupakan alat untuk mengukur percepatan, mendeteksi juga mengukur getaran dan percepatan akibaat gravitasi (Yunasa dkk, 2015). Dengan penggunaan accelerometer pada game android tidak hanya membutuhkan tombol atau media lain untuk mengontrol permainan, misalnya dengan memiringkan smartphone tersebut maka player akan bergerak dengan sendirinya tanpa menyentuh tombol, sehingga game terasa semakin unik dan semakin menarik, sehingga menjadi cara untuk menyajikan materi belajar dan bermain dengan cara yang menarik bagi semua siswa.

Sebelumnya terdapat beberapa jurnal yang membahas tentang aplikasi belajar dan bermain yaitu "game edukasi mengenal pembelajaran aksara jawa untuk siswa sekolah dasar dengan menggunakan media broadgame" didapatkan hasil bahwa siswa menjadi lebih menguasai dan berminat terhadap aksara Jawa setelah memainkan boardgame "Tepok Aksara" (Avianto dan Prasida, 2018). "Pengembangan media sinau maca aksara jawa (si marja) dalam mata pelajaran bahasa jawa kelas IV SDN Keputran A Yogyakarta" didapatkan hasil layak digunakan karena memenuhi beberapa kriteria dan memberikan motivasi bagi siswa (Kusuma, 2015). "Game aplikasi pengenalan aksara jawa "Hanacaraka" berbasis android" didapatkan hasil dapat meningkatkan minat siswa dalam memahami jenis-jenis aksara Jawa (Nisa dkk, 2017).

Berdasarkan uraian di atas dapat disimpulkan bahwa media yang dapat digunakan dalam belajar dan bermain sangat banyak dan masing-masing memiliki keunikan tersendiri. Maka dari hal tersebut penulis membuat aplikasi game edukasi untuk mengenal aksara jawa berbasis android, yaitu dengan judul Game Edukasi Aksara Jawa 3D Dengan Accelerometer. Aplikasi ini dibuat menggunakan Unity 3D dan juga menerapkan control accelerometer ke dalam game, terdapat pembelajaran tentang aksara jawa dasar, tampilan yang menarik dan mudah di pahami. Dengan adanya game edukasi yang memanfaatkan teknologi smartphone, aplikasi android dan juga control accelerometer dapat menarik minat anak-anak didik dalam mengenal aksara jawa.

\subsection{Rumusan Masalah}

Berdasarkan uraian pada latar belakang masalah, dapat diidentifikasi beberapa masalah sebagai berikut:

1. Bagaimana membuat game edukasi untuk mengenalkan Aksara Jawa 3D kepada anak Sekolah Dasar.

2. Bagaimana menerapkan accelerometer sebagai kontrol gerak player dalam Game Edukasi Aksara Jawa 3D.

\subsection{Batasan Masalah}

Agar pembahasan tidak menyimpang dari pokok permasalahan, maka perlu dibuat batasan masalah sebagai berikut:

1. Aplikasi offline.

2. Software yang digunakan dalam membuat game ini adalah Unity 5.6.3f1(64-bit)

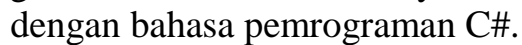

3. Pergerakan player menggunakan sensor accelerometer .

4. Materi yang disajikan dalam media pembelajaran menyangkut pokok bahasan pengenalan sejarah aksara jawa, aksara hanacaraka dan sandangan untuk siswa sekolah dasar.

\subsection{Tujuan Penelitian}

Sesuai dengan rumusan masalah di atas, maka penelitian ini bertujuan :

1. Membangun Game Edukasi Aksara Jawa 3D sehingga dapat menambah pengetahuan anak sekolah dasar dalam mengenal aksara jawa.

2. Menerapkan acceleratometer senagai kontrol gerak dalam Game Edukasi Aksara Jawa 3D.

\section{KAJIAN PUSTAKA \\ 2.1 Tinjauan Pustaka}

Berdasarkan studi kepustakaan dan observasi yang dilakukan oleh peneliti, telah ditemukan kasus yang sama dilakukan oleh peneliti lain sebelumnya mengenai media pembelajaran interaktif berbasis android dengan metode yang berbeda dan objek yang berbeda antara lain :

1. Pembelajaran aksara jawa untuk siswa sekolah dasar dengan menggunakan media broadgame (Avianto dan Prasida, 2018).

2. Pengembangan media sinau maca aksara jawa (si marja) dalam mata pelajaran bahasa jawa kelas IV SDN Keputran A Yogyakarta (Kusuma, 2015). 
3. Game aplikasi pengenalan aksara jawa "hanacaraka" berbasis android (Nisa dkk, 2017).

Dari penelitian tersebut, banyak macam bentuk aplikasi media yang digunakan dalam media pembelajaran, oleh karena itu penelitian ini akan mengembangkan aplikasi belajar aksara jawa dengan bentuk yang baru, yaitu membuat Game Edukasi Aksara Jawa 3D dengan Accelerometer sehingga dapat menambah pengetahuan anak didik dalam mengenal aksara jawa.

\subsection{Landasan Teori}

\subsubsection{Aksara Jawa}

Aksara Jawa merupakan salah satu peninggalan budaya bangsa Indonesia yang tidak ternilai harganya. Bentuk aksara dan seni pembuatannya menjadi suatu peninggalan yang harus dilestarikan. Aksara Jawa merupakan aksara tradisional nusantara yang digunakan untuk menulis bahasa Jawa (Nisa dkk, 2017).

\subsubsection{Game}

Game diambil dari kata dalam bahasa inggris artinya permainan. Memainkan game merupakan salah satu metode belajar yang digunakan dalam interaksi antar sejumlah pemain maupun perorangan yang menunjukkan strategi agar bisa menang. Dalam dunia pisikologi kegiatan bermain di pandang sebagai suatu kegiatan yang mengandung keasyikan dan dilakukan atas kehendak sendiri, bebas tanpa paksaan dengan tujuan untuk memperoleh kesenangan pada waktu kegiatan tersebut (Wardani, 2009).

\subsubsection{Android}

Android yaitu suatu sistem operasi yang digunakan untuk perangkat mobile berbasis linux yang mencakup sistem operasi, middleware dan aplikasi. Android menyediakan platform yang terbuka bagi para pengembang untuk berinovasi dan menciptakan aplikasi mereka. Pada Awalnya, Google Inc. membeli Android Inc. yang merupakan pendatang baru yang membuat peranti lunak untuk ponsel atau smartphone (Safaat, 2012).

\subsubsection{Accelerometer}

Accelerometer adalah salah satu sensor yang digunakan untuk mengukur percepatan suatu objek. Accelerometer juga merupakan sensor dinamis yang mampu melakukan berbagai macam penginderaan. Sensor accelerometer dapat mengukur percepatan dalam satu, dua, atau tiga sumbu. Accelerometer juga merupakan salah satu fitur yang ditanam pada smartphone android (Yunasa dkk, 2015).

\section{METODE PENELITIAN}

\subsection{Metodologi Penelitian}

\subsubsection{Instrumen Penelitian}

Instrumen penelitian adalah alat bantu yang digunakan oleh peneliti dalam melakukan kegiatannya untuk mengumpulkan data dan memprosesnya agar kegiatan tersebut menjadi sistematis dan dipermudah. Instrumen yang digunakan berupa hardware dan software peneliti yaitu :

Tabel 1. Hardware yang digunakan

\begin{tabular}{cc}
\hline No. & Hardware \\
\hline 1 & Laptop Lenovo G-400 \\
2 & HP OPPO A37f
\end{tabular}

Tabel 2. Software yang digunakan

\begin{tabular}{ll}
\hline No. & \multicolumn{1}{c}{ Software } \\
\hline 1 & Windows 8.1 \\
2 & Unity 3D Versi 5.63f1 \\
3 & Blender \\
4 & Android SDK \\
5 & Adobe Photoshop \\
6 & Adobe Audition
\end{tabular}

\subsubsection{Metode Pengumpulan Data}

Metode Pegumpulan data yang dilakukan peneliti dalam penelitian ini dengan cara observasi yaitu melakukan pengamatan langsung terhadap objek penelitian dan mencatat hal-hal penting yang berkaitan dengan penelitian. Melakukan wawancara kepada pihak-pihak terkait serta pengumpulan data kepustakaan dan jurnal dengan menggunakan sumber-sumber tertulis guna memperoleh gambaran secara teoritis yang lengkap dan akurat.

\subsubsection{Metode Pengembangan Perangkat Lunak}

Metode yang digunakan dalam pengembangan multimedia di antaranya adalah Multimedia Development Life Cycle yang terdiri dari enam tahap yaitu, concept (konsep), design (desain), material collecting (pengumpulan materi), assembly (pembuatan), testing (pengujian), dan distribution (pendistribusian). (Binanto, 2010). 


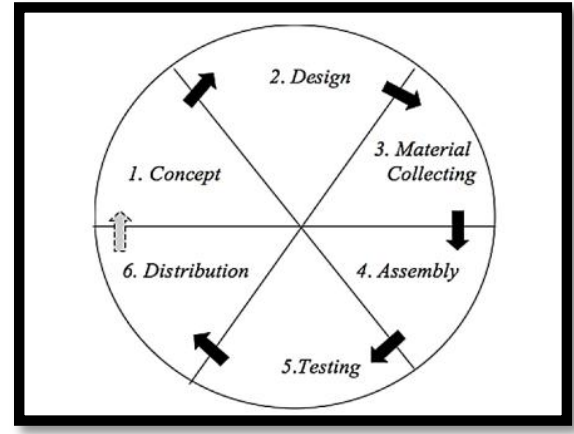

Gambar 1. MDLC Diagram

\section{ANALISIS dan PERANCANGAN}

\subsection{Analisis}

\subsubsection{Analisis Sistem yang Sedang Berjalan}

Analisis pada sistem yang berjalan bertujuan untuk mengidentifikasi dan mengevaluasi sistem pada penerapan teknologi Game Edukasi Aksara Jawa 3D dengan Accelerometer. Adapun masalah yang ada pada penelitian ini yaitu menjadikan suatu pengenalan dan pembelajaran aksara jawa secara mobile dan menyenangkan. Analisis dilakukan agar dapat menemukan masalahmasalah dalam melakukan pengembangan sistem yang diperlukan yang diberikan oleh pihak pengguna.

\subsubsection{Analisis Kebutuhan Sistem}

Analisis kebutuhan

sistem menggambarkan kebutuhan yang diperlukan untuk menjalankan aplikasi yang dibuat. Kebutuhan dalam pembuatan aplikasi ini meliputi kebutuhan perangkat keras (Hardware), kebutuhan perangkat lunak (Software), kebutuhan pengguna yaitu :

Tabel 3. Perangkat keras

\begin{tabular}{ll}
\hline No. & \multicolumn{1}{c}{ Perangkat Keras } \\
\hline 1 & Laptop Lenovo G-400 \\
2 & Mouse NafeeG5 \\
3 & Smartphone OPPO A37f \\
4 & Mic Taffware BM8000
\end{tabular}

Tabel 4 Perangkat lunak

\begin{tabular}{ll}
\hline No. & \multicolumn{1}{c}{ Perangkat Lunak } \\
\hline 1 & Sistem Operasi Windows 8.1 \\
2 & Android SDK \\
3 & UNITY 3D 5.6.3f1 \\
4 & Adobe Phothosop CS6 \\
5 & Adobe Audition CS6 \\
6 & Blender
\end{tabular}

\subsection{Perancangan}

4.2.1 Perancangan Permodelan UML

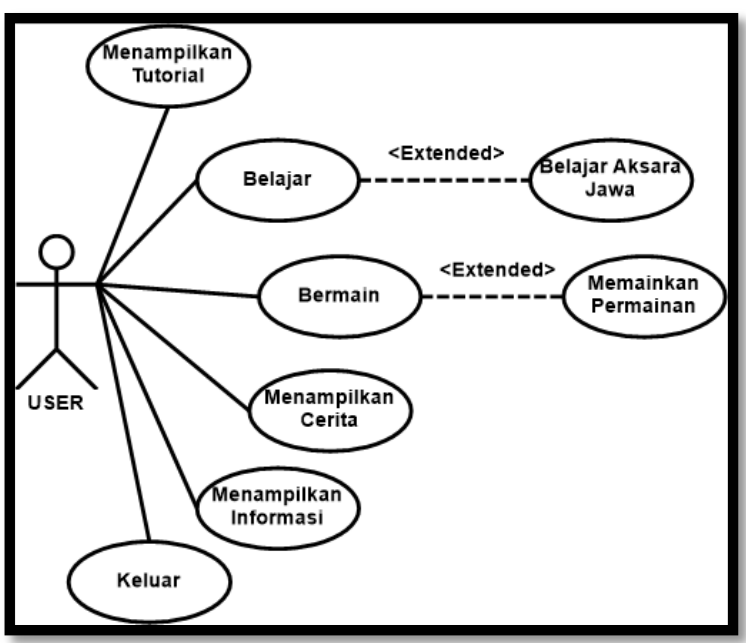

Gambar 2. UML

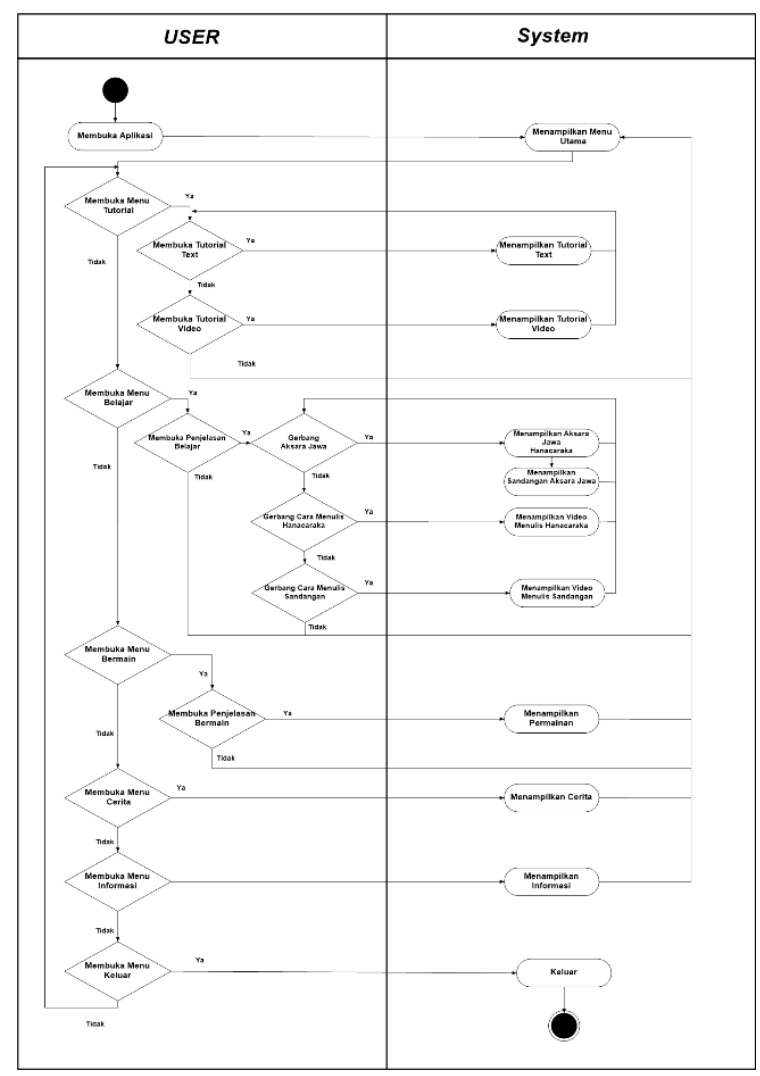

Gambar 3. Activity Diagram 


\subsubsection{Perancangan Struktur Menu}

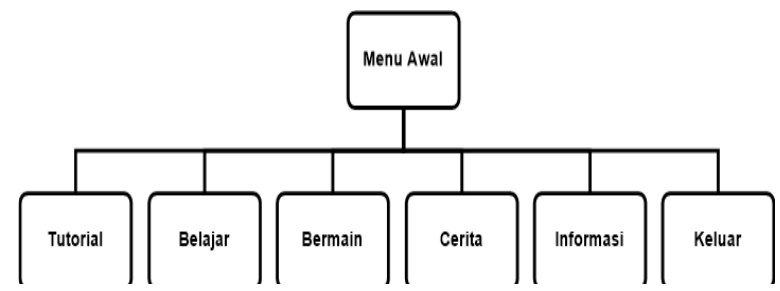

Gambar 4. Struktur menu

\section{HASIL dan PEMBAHASAN}

\subsection{Halaman Pembuka}

Halaman splash screen merupakan pembukaan dimana pada halaman ini terdapat logo pembuat serta logo Universitas Wahid Hasyim Semarang. Halaman ini akan tampil hanya beberapa detik.

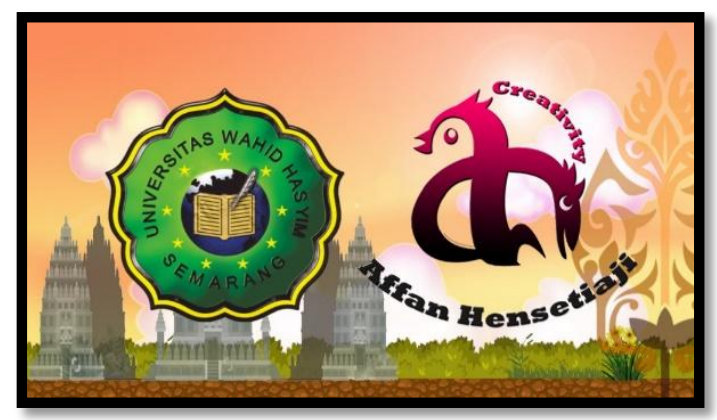

Gambar 5. Halaman splash screen

\subsection{Halaman Loading}

Halaman loading pada halaman ini terdapat garis lurus putih yang nantinya akan penuh terisi warna orange yang menujukan loading selesai. Halaman ini akan tampil hanya beberapa detik.

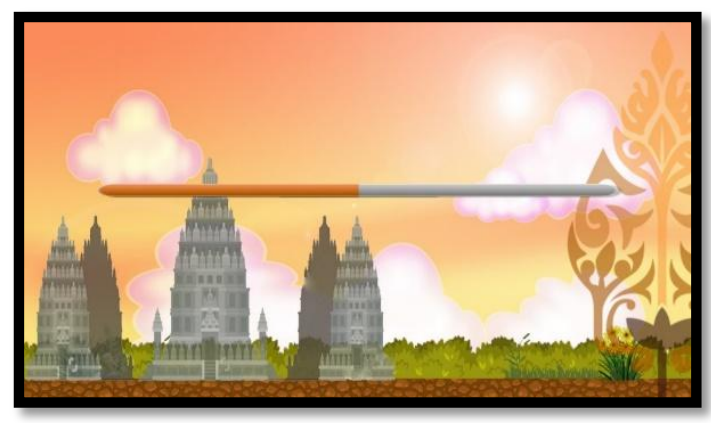

Gambar 6. Halaman loading

\subsection{Halaman Menu Utama}

Halaman utama pada game yang mana meliputi tombol menu. Halaman ini terdapat enam tombol navigasi yaitu tombol tutorial, tombol belajar, tombol cerita, tombol informasi dan yang terahir yaitu tombol keluar.

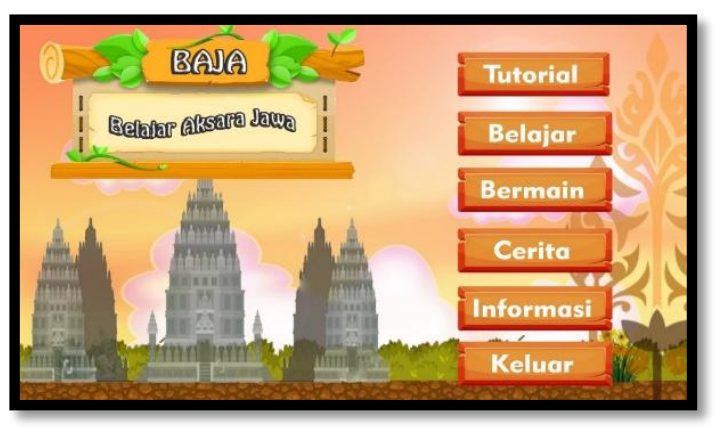

Gambar 7. Halaman menu utama

\subsection{Halaman Tutorial}

Halaman tutorial merupakan halaman yang menjelaskan tentang bagaimana cara menggunakan aplikasi ini dan memainkan permainannya.

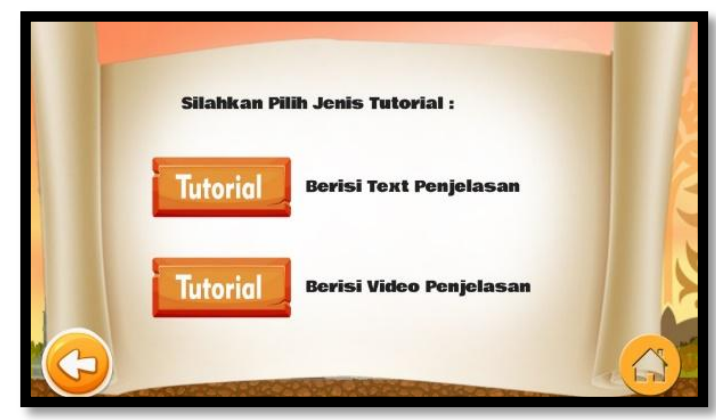

Gambar 8. Halaman tutorial

\subsection{Halaman Tutorial Text}

Halaman tutorial yang menjelaskan dalam bentuk text.

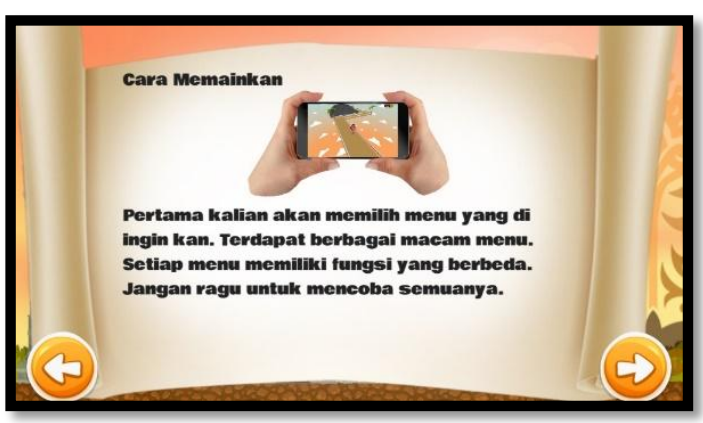

Gambar 9. Halaman tutorial text

\subsection{Halaman Tutorial Video}

Halaman tutorial yang menjelaskan dalam bentuk video. 


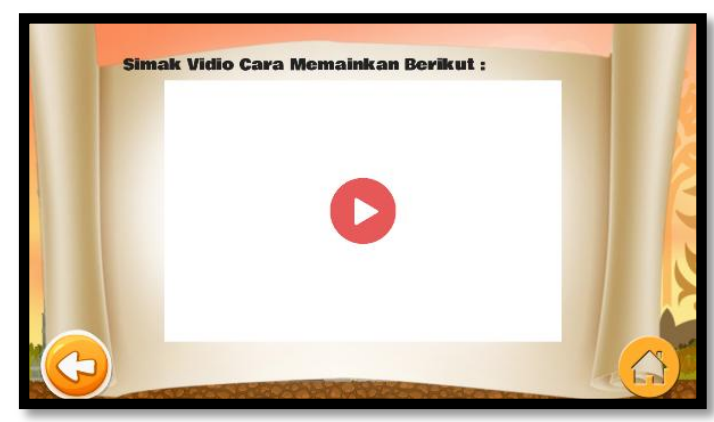

Gambar 10. Halaman tutorial video

\subsection{Halaman belajar}

Halaman yang berfungsi penjelasan singkat dan peraturan belajar sebelum menuju ke halaman memilih portal belajar .

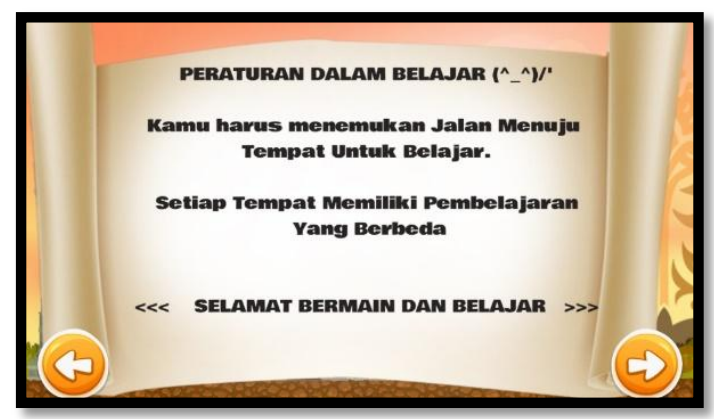

Gambar 11. Halaman belajar

\subsection{Halaman Memilih Portal Belajar}

Pengguna harus memiringkan atau mencondongkan smartphone agar player bergerak yang dikarenakan player menggunakan control accelerometer. Pada halaman ini terdapat tombol gear yang berfungsi sebagai pause menu. Ketika hendak mendekati jalan maka akan keluar layar pemberitahuan jalan yang dituju.

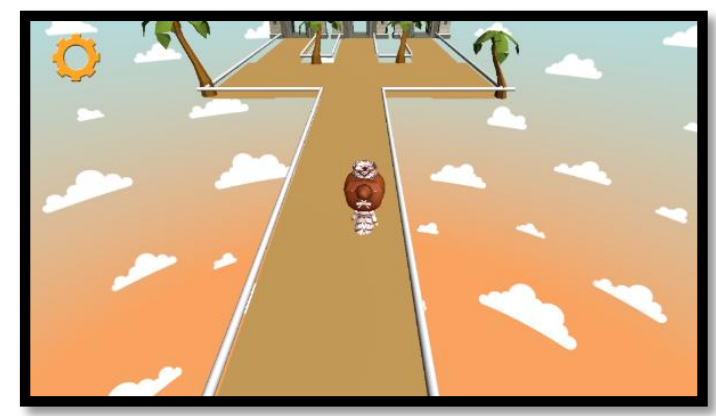

Gambar 12. Halaman memilih portal belajar 5.9 Halaman Tulisan Aksara Jawa
Halaman untuk belajar mengenal aksara jawa dasar yang bisa disebut aksara nglegena/carakan/hanacaraka.

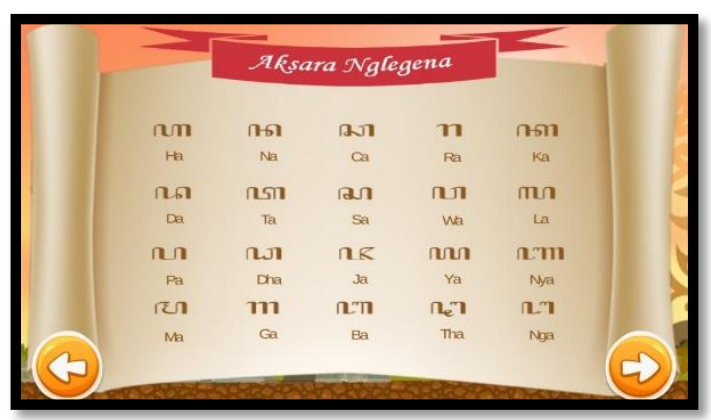

Gambar 13. Hanacaraka

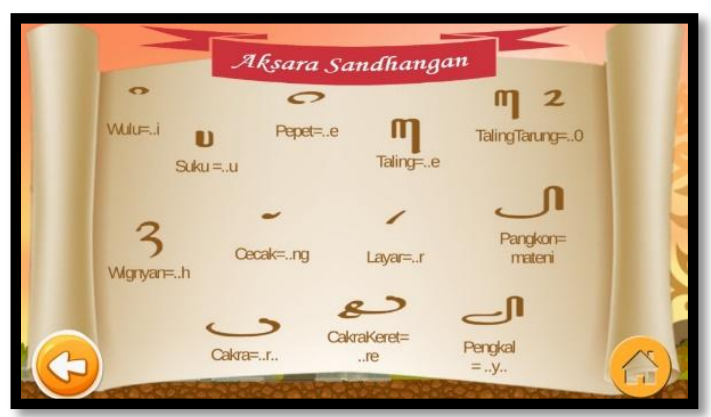

Gambar 14. Sandangan

\subsection{Halaman Cara Menulias Aksara Jawa}

Merupakan halaman untuk belajar mengenal aksara jawa dasar dan melihat cara menulis aksara jawa tersebut menggunakan alat tulis melalui video .

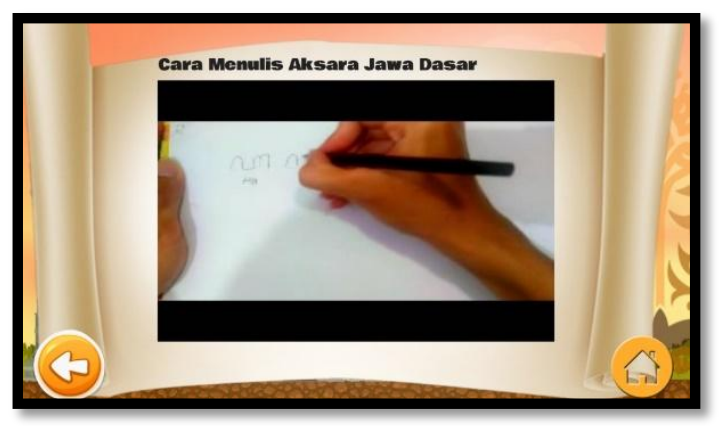

Gambar 15. Cara menulis aksara jawa hanacaraka

\subsection{Halaman Cara Menulis Sandangan}

Merupakan halaman untuk belajar mengenal sandangan aksara jawa dan melihat cara menulis sandangan aksara jawa tersebut menggunakan alat tulis serta dilengkapi cara penggunaannya melalui video. 


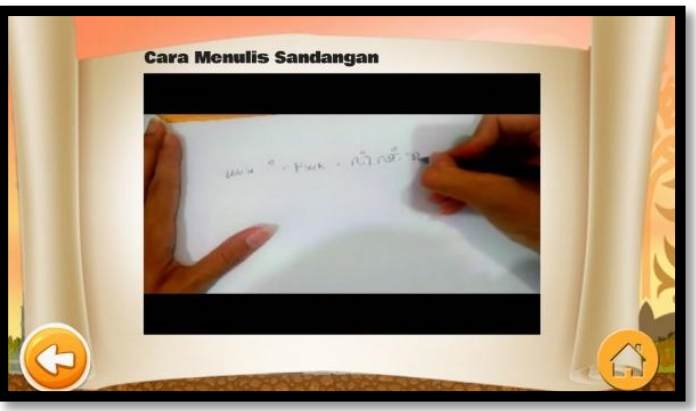

Gambar 16. Cara menulis sandangan

\subsection{Halaman Bermain}

Pengguna akan diberikan penjelasan singkat dan peraturan bermain sebelum menuju ke halaman selanjutnya. Terdapat 3 area. Pengguna diharuskan melewati objek yang telah di beritahu oleh petunjuk yang ada pada setiap area.

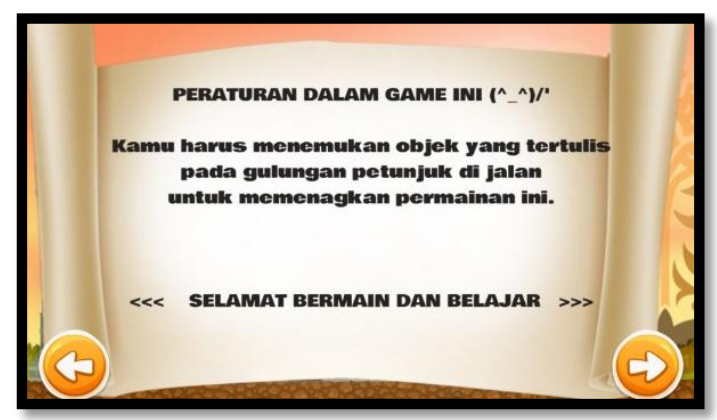

Gambar 17. Peraturan bermain

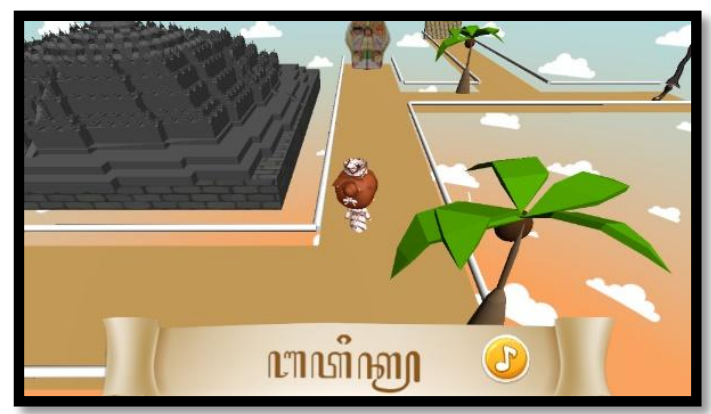

Gambar 18. Area 1

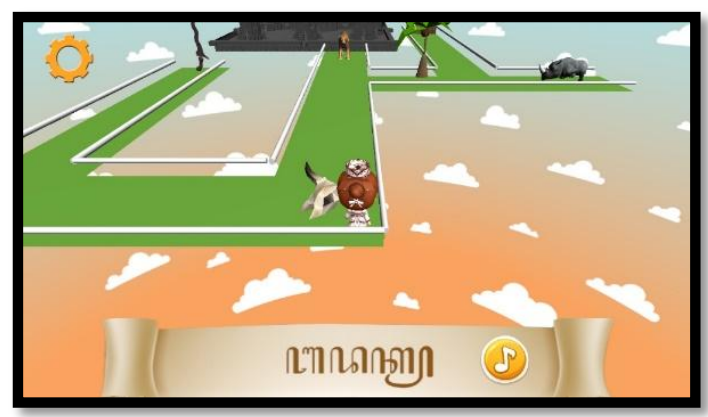

Gambar 19. Area 2

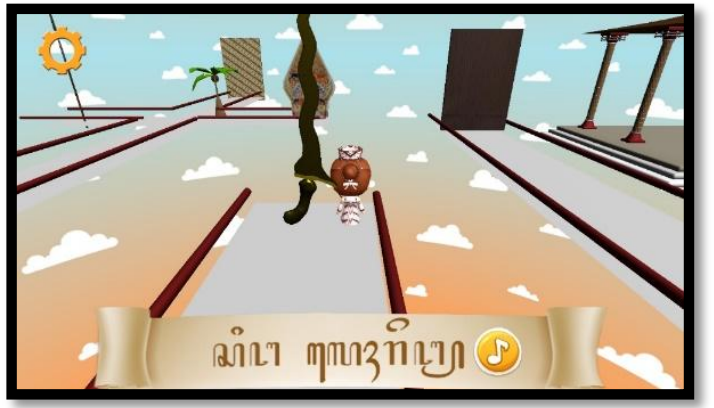

Gambar 20. Area 3

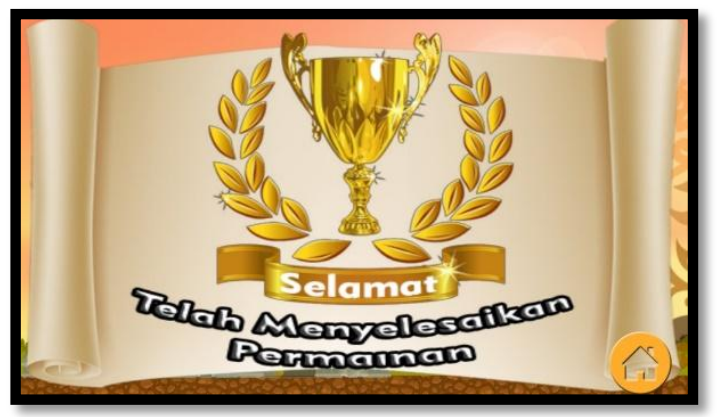

Gambar 21. Telah menyelesaikan permainan

\subsection{Halaman Cerita}

Halaman untuk mengetahui cerita sejarah asal mula aksara jawa melalui media video.

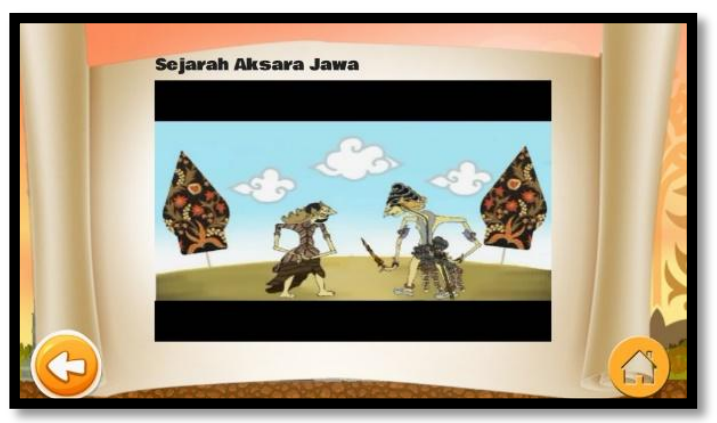

Gambar 22. Halaman cerita

\subsection{Halaman Informasi}

Halaman untuk mengetahui informasi tujuan, fungsi dan pembuat game ini.

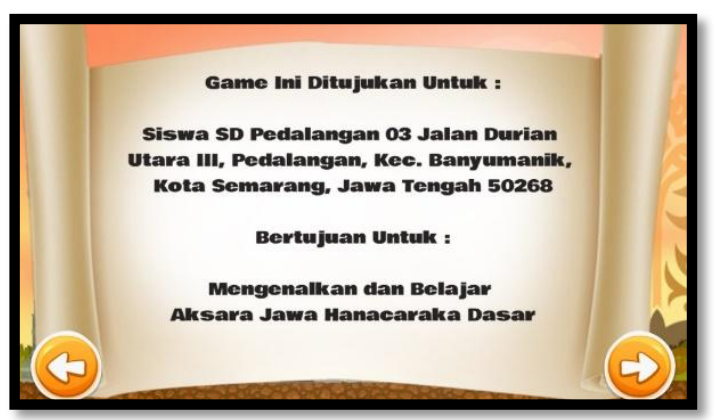

Gambar 23. Halaman informasi 


\subsection{Halaman Keluar}

Berfungsi untuk keluar dari permainan.

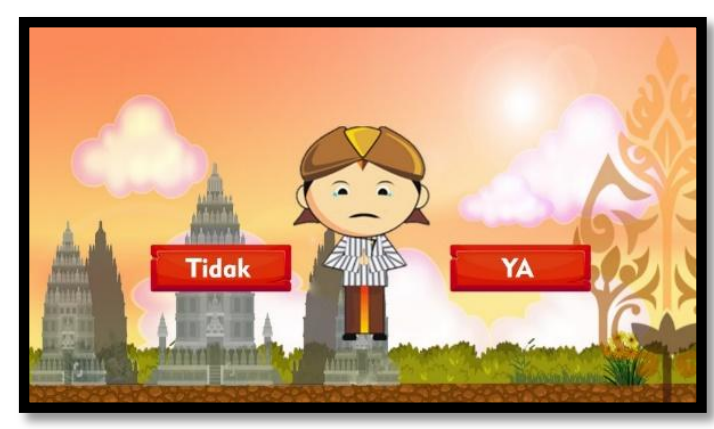

Gambar 24. Halaman keluar

\section{KESIMPULAN dan SARAN \\ 6.1 Kesimpulan}

Dari hasil penelitian ini, dapat diambil kesimpulan sebagai berikut :

1. Game Edukasi Aksara Jawa 3D yang berbasis android telah berhasil menyajikan cara bermain dan belajar aksara jawa yang menarik untuk dimainkan dan mampu memberikan pengetahuan tentang aksara jawa dasar kepada murid Sekolah Dasar.

2. Game Edukasi Aksara Jawa 3D ini telah berhasil memanfaatkan sensor accelerometer yang ada di dalam smartphone sebagai kontrol gerak dalam game sehingga menjadikan permainan lebih unik dan menarik untuk di mainkan.

\subsection{Saran}

Game edukasi aksara jawa 3D dengan accelerometer yang berbasis android ini dapat dikembangkan lagi agar :

1. Game saat ini dibuat untuk media android, diharapkan pada penelitian selanjutnya aplikasi ini bisa dikembangkan untuk versi website maupun dekstop.

2. Lagu pada game edukasi aksara jawa 3D dengan accelerometer ini dapat diperbanyak lagi sehingga lebih bervariasi.

\section{DAFTAR PUSTAKA}

Avianto, Y.F., Prasida, T.A.S., 2018, Pembelajaran Aksara Jawa Untuk Siswa Sekolah Dasar Dengan Menggunakan Media Board Game, Salatiga.

Binanto, I., 2010, Multimedia Digital Dasar Teori dan Pengembangannya, Andi, Yogyakarta.

Kusuma, E.A., 2015, Pengembangan Media Sinau Maca Aksara Jawa (Si Marja)
Dalam Mata Pelajaran Bahasa Jawa Kelas IV SD N Keputran A Yogyakarta, Yogyakarta.

Mustagfirin., Toto, H., Dwi, P., 2019, Adaptasi Media Digital Dalam Revitalisasi Artifak Masjid Agung Demak Di Era 4.0, Jurnal SENS4 Vol.1 No.1, Semarang.

Nisa, P.L.K., Maknunah, J., Syaifulloh, A., 2017, Game Aplikasi Pengenalan Aksara Jawa "Hanacaraka" Berbasis Android, Seminar Nasional Sistem Informasi (ISSN : 2597 - 4696), Malang.

Syafaat, N.H., 2012,Pemrograman Aplikasi Mobile Smartphone dan Tablet PC Berbasis Android, Informatika Bandung, Bandung.

Wardani, D., 2009, Bermain Sambil Belajar, Edukasia, Bandung.

Yunasa, R., Rumani, R.M., Saputra, R.E., 2015, Implementasi Accelerometer Pada Smartphone Android Sebagai Media Player Controller Pada Pc, e-Proceeding of Engineering (ISSN : 2355-9365) Vol.2 No.2, Bandung. 